\title{
PERCEPTIONS OF PHYSICIANS ABOUT CLINICAL PHARMACIST'S ROLE IN AL QASSIM'S HOSPITALS IN SAUDI ARABIA
}

\author{
Nahid Osman Ahmed ${ }^{1 *}$, Mahfoudh A. M. Abdulghani ${ }^{2}$, Sarah Fahad Alrebdi ${ }^{1}$ and Mohammed Faez \\ Baobaid $^{3}$ \\ ${ }^{1}$ Department of pharmacy practice, college of Pharmacy, Qassim University, Saudi Arabia \\ 2Department of Pharmacology \& Toxicology, Unaizah College of Pharmacy, Qassim University, Saudi Arabia \\ ${ }^{3}$ Public health Department, International medical School, Management and Science University, Malaysia
}

Corresponding author:

Nahid Osman Ahmed

Email: nantish@hotmail.com

\begin{abstract}
The objective of this study is to explore physician's perception toward clinical pharmacy services and role of clinical pharmacists in governmental hospitals at Al-Qassim region. An observational cross-sectional survey was conducted. Results: 150 males and 39 females participated giving 75.5\% (189 of 250) response rate. Physicians perceptions were found to be high (equal or more than $90 \%$ of frequency) in some clinical pharmacy services such as patients' education and counselling, monitoring of patients' responses to drug therapy including toxicity/side effects and provision of drug information to healthcare professionals. The physicians showed low perception (less than 76\%) in the taking of patients' medication history on admission, by clinical pharmacists. Conclusion: Physicians' perception toward clinical pharmacy services and the role of clinical pharmacists was not found to be completely favourable. The reason of this mixed responses and to the accommodating feelings of clinical pharmacy services in clinical setting appear to relate to the state of infrastructure and environments of hospitals. The infrastructure and environments of hospitals need to be updated for an improved accommodation clinical pharmacy services.
\end{abstract}

Key words: Clinical Pharmacist services, Patient care, Physician, Perception, Saudi Arabia

\section{INTRODUCTION}

Services and activities of clinical pharmacy have several descriptions and definitions. According to American College of Clinical Pharmacy (ACCP) the services of clinical pharmacy (SPCs) is described as embodiment of the application of the scientific principles of pharmacology, toxicology, pharmacokinetics and therapeutics to the care of patients. Also, the SPCs are described by United States Department of Health and Human Services (USDHHS) as identifying, resolving and preventing of drug-related problems. European Society of Clinical Pharmacy (ESCP) described the SPCs as developing and promoting the rational and appropriate use of medicinal products and devices ${ }^{1}$. The SCPs mainly focus on patients' care through optimizing of drug therapy which can be described as safe, effective, appropriate, affordable, cost-effective and personalized to meet the needs of patients ${ }^{2}$.

In Saudi Arabia, the SCPs were introduced in 1970 s by US clinical pharmacists through the adoption of pharmacokinetic, parenteral nutrition, and drug information services at the King Faisal Specialist Hospital. Remarkable progress in integration of SCPS in clinical setting of hospitals achieved during the last 15 years through the development and adoption of standards of clinical pharmacy implemented in the US ${ }^{3}$. To date, the applied SCPs is being offered with different scope (size and depth) in
Saudi Arabian hospitals. More than 30 SCPs have been reportedly offered by hospitals in many clinical areas $^{4}$. The established SCPs relates clinical pharmacists' involvements with the healthcare teams and pharmacist-run clinics, beside traditional services of pharmacy dispensing, management of medication storage and supplies. The clinical areas involvement include adult-oncology, paediatric-oncology, solid organ transplant, ambulatory care, general surgery, adult surgical and medical intensive care, neonatal and paediatric intensive care, nephrology, internal medicine, anticoagulation, cardiology, pain management, drug information, infectious diseases, haematology, parenteral nutrition, investigational drug services discharge, and medication-use evaluation (MUE) service. The available pharmacist-run clinics include anticoagulation, cardiology, HIV, oncology, pain, solid organ transplant, and ambulatory care. Moreover, several hospitals render 24-hrs on-call services of clinical pharmacists for pressing issues that need to be addressed under emergency settings. Furthermore, hotline calls on national drug information 24/7 days is available, providing needed services to both the public and professionals ${ }^{4,5}$.

Although these services were long established, and Saudi Arabia is considered as one of the countries with the best hospital clinical pharmacy practice culture in the region, some SCPs have reportedly been poorly practiced in 
some hospitals. Such services include retrospective drug-use evaluations, identification of problem-prone or high-risk therapies using pre-established criteria, routine review of culture \& sensitivity reports and tracking and trending treatment failures ${ }^{5}$. These have in part been attributed to the presence of policy gaps between clinical pharmacy practices and the hospital setting ${ }^{3}$. . In standard hospital settings, clinical pharmacists are involved in medicationrelated and regulatory issues including verification and dispensing, provision of drug information to other health care providers, preparation of sterile medications or chemotherapies and parenteral nutrition, identification and reporting of adverse drug events (ADEs) or pharmacovigilance and a medication error reporting program ${ }^{4}$. In order for clinical pharmacists to adequately provide the SCPs, collaboration should be made between clinical pharmacists and members of healthcare team like physicians ${ }^{1}$. There are a range of evidences in literature that physicians are receptive to many of the SCPs provided by pharmacists. However, the physicians often tend to have positive attitude if the SCPs are provided as a consultation or in in a manner that supports manner among the knowledge-sharing to improve patient care $^{6-8}$. Some studies however reported that physicians showed resistance for clinical services of clinical pharmacists, which is attributed to the non-participation of physicians in clinical pharmacist activities ${ }^{9-11}$.

In Kuwait approximately $50 \%$ of 120 physicians responded positively on the implementation of patient-oriented roles of clinical pharmacists such as designing pharmacotherapeutic regimes, monitoring outcomes of pharmacotherapeutic regimens and detecting errors prescription ${ }^{14}$. In United Arab Emirates (UAE) about 25\% of 285 physicians showed that pharmacists can be a trusted source of clinical information, and costeffective medicine ${ }^{15}$. In Saudi Arabia one study reported that physicians at Riyadh hospitals showed positive attitude about SCPs by clinical pharmacists to the extent that the physicians accepted the clinical pharmacists as an integral part of the medical team (mean $4.4 \pm 0.72$ ) and the useful role of clinical pharmacists in management of drug interactions and side effects, educate other healthcare employees, and selection of appropriate treatment during pregnancy $^{16}$. To our knowledge, no study was conducted on physician's perception of clinical pharmacy services in Qassim hospitals. This study is therefore undertaken to explore the perception of physicians in three governmental hospitals at Al Qassim region toward clinical pharmacy services provided by clinical pharmacists.

\section{MATERIALS AND METHODS}

Physicians from different specialties and years of experience in three governmental hospitals in Qassim; King Fahad Specialist Hospital, Maternity and Children Hospital of Buraidah and Buraidah Central Hospital who voluntarily agreed to participate in the study from the period (10 October 2016 to 30 April 2017). Total number of physicians enrolled were 189 . The study design is an observational cross-sectional survey. Data was collected by direct face to face interview using a structured questionnaire designed in 2 sections. Section A contains 6 questions and it represents demographic characteristics of the physicians. Section B contains 12 questions and it represents attitude of the physicians towards clinical pharmacy services ${ }^{17}$. 5-point Likert scale was used and strongly agree and agree were aggregated as positive response and strongly disagree and disagree also aggregated as negative response. Research proposal was approved from the college of pharmacy, research unit and the Regional Research Ethics Committee and King Fahad Specialist Hospital, Maternity and Children Hospital of Buraidah and Buraidah Central Hospital research committees.

\section{Data analysis}

Data was analysed using computer based Statistical Package for Social Science (SPSS, Inc., Chicago, IL, USA) version 24. Data was represented in frequency, percentage, mean and standard deviation (SD). Scheffe test and t-test was used to identify the difference in positive response to questions. The level of significance was set at $P<0.05$.

\section{RESULTS}

Of the total 250 surveys distributed to the physicians, 189 surveys were returned giving a response rate of $75.5 \%$. The majority of the respondents were male $(n=150,79.4 \%)$. The ages of the majority of respondents were $\geq 35$ years. Specialist, residents, and consultants as positions of the respondents were found. Half of the respondents have work experience in healthcare system more than 10 years. The total years of experience of respondents in healthcare setting having clinical pharmacy services ranged from less than one year to more than three years Table 1. 
Table 1: Demographic characteristics

\begin{tabular}{|c|c|c|}
\hline Characteristics & Category & N (\%) \\
\hline \multirow[t]{2}{*}{ Gender } & Male & $150(79.4)$ \\
\hline & Female & $39(20.6)$ \\
\hline \multirow[t]{2}{*}{ Age (in years) } & $\geq 35$ & $123(65.1)$ \\
\hline & $<35$ & $66(34.9)$ \\
\hline \multirow[t]{3}{*}{ Position } & Consultant & $41(21.7)$ \\
\hline & resident & $72(38.1)$ \\
\hline & Specialist & $76(40.2)$ \\
\hline \multirow[t]{8}{*}{ Current area of practice } & Emergency Medicine & $23(12.2)$ \\
\hline & General Surgery & 35 ( 18.5) \\
\hline & Gynecology/Obstetrics & $12(6.3)$ \\
\hline & Internal medicine & $22(11.6)$ \\
\hline & Oncology & $11(5.8)$ \\
\hline & Orthopedic & $13(6.9)$ \\
\hline & Pediatrics & $16(8.5)$ \\
\hline & Others & $57(30.2)$ \\
\hline \multirow[t]{4}{*}{$\begin{array}{l}\text { Work experience in healthcare system } \\
\text { ( years) }\end{array}$} & $<2$ & $14(7.4)$ \\
\hline & $2-5$ & $35(18.4)$ \\
\hline & $6-10$ & $44(23.3)$ \\
\hline & $>10$ & $96(50.8)$ \\
\hline \multirow[t]{4}{*}{$\begin{array}{l}\text { Total of experience in health setting with } \\
\text { provision of clinical pharmacy service(years) }\end{array}$} & None & $49(25.9)$ \\
\hline & $<1$ & $21(11.1)$ \\
\hline & $1-3$ & 39 ( 20.6) \\
\hline & $>3$ & $80(42.3)$ \\
\hline
\end{tabular}

Perceptions of the respondents toward clinical pharmacy services:

The overall mean perception and standard deviation was $4.1 \pm 0.7$ which indicates that general perception of the respondents on the 12 items on clinical pharmacy services is positive. In the items $1-5$ and 12 , the respondents showed highly positive perception (approximately 90\%) toward services of clinical pharmacists (SCPs) in medical ward round, patient education and counselling, monitor response of patient to drug therapy from perspective of side effects and effectiveness, provision drug information to healthcare teams and these SCPs can improve overall care outcome and quality of patients. In other items 6-9 the positive perceptions of the respondents showed moderate positive perception (approximately 78\%) on SCPs that can make enhancement of patients' satisfaction, documentation of SCPs by clinical pharmacists in patients' chart and analyses patient treatment with change suggestion if necessary. In item 10 which the respondents moderate feeling $75.7 \%$ that SCPs should be focused more on drug products rather than on care of patient. In item 11 , the respondents showed faire feeling $63.55 \%$ on current setup of their hospitals are suitable to provide SCPs. (Table 2 ). 
Table2: Perceptions of respondents towards clinical pharmacy services

\begin{tabular}{|c|c|c|c|}
\hline \multirow[b]{2}{*}{ Perception items } & \multicolumn{3}{|c|}{ Degree of approval } \\
\hline & $\begin{array}{l}\text { Positive } \\
\text { n (\%) }\end{array}$ & $\begin{array}{c}\text { Normal } \\
\mathrm{n}(\%)\end{array}$ & $\begin{array}{l}\text { Negative } \\
\mathrm{n}(\%)\end{array}$ \\
\hline $\begin{array}{l}\text { Participation of clinical pharmacist in medical ward round is } \\
\text { desirable. }\end{array}$ & $167(88.4)$ & $11(5.8)$ & $11(5.8)$ \\
\hline $\begin{array}{l}\text { Clinical pharmacist can play important role in patient education } \\
\text { and counseling. }\end{array}$ & $172(91)$ & $8(4.2)$ & $9(4.8)$ \\
\hline $\begin{array}{l}\text { Clinical pharmacist can monitor response of patient to drug } \\
\text { therapy from toxicity/side effects perspective. }\end{array}$ & $173(91.5)$ & $11(5.8)$ & $5(2.6)$ \\
\hline $\begin{array}{l}\text { Clinical pharmacist can monitor response of patient to drug } \\
\text { therapy from effectiveness perspective. }\end{array}$ & $164(86.8)$ & $16(8.5)$ & $9(4.8)$ \\
\hline $\begin{array}{l}\text { Clinical pharmacist can provide drug information to health care } \\
\text { professionals, such as compatibility, stability, storage, } \\
\text { availability. }\end{array}$ & $178(94.2)$ & $10(5.3)$ & $1(0.5)$ \\
\hline $\begin{array}{l}\text { Clinical pharmacy services enhance patients appreciation and } \\
\text { satisfaction. }\end{array}$ & 145 (76.7) & $26(13.8)$ & $18(9.5)$ \\
\hline $\begin{array}{l}\text { Clinical pharmacist should take patients medication history at } \\
\text { admission. }\end{array}$ & $143(75.7)$ & $28(14.8)$ & $18(9.5)$ \\
\hline $\begin{array}{l}\text { Clinical pharmacist should have access to patients chart and have } \\
\text { a place to document their service. }\end{array}$ & $156(82.5)$ & $18(9.5)$ & $15(7.9)$ \\
\hline $\begin{array}{l}\text { Clinical pharmacist should analyses patient treatment and } \\
\text { suggest changes of therapy when necessary. }\end{array}$ & $155(82)$ & $23(12.2)$ & $11(5.8)$ \\
\hline $\begin{array}{l}\text { Clinical pharmacist should care about drug products and leave } \\
\text { patient care to Doctors, Health Officers and nurses. }\end{array}$ & $143(75.7)$ & $14(7.4)$ & $32(16.9)$ \\
\hline $\begin{array}{l}\text { The current setup (infrastructure and environments of your } \\
\text { hospital is appropriate for the provisions of clinical pharmacy } \\
\text { service. }\end{array}$ & $120(63.5)$ & $25(13.2)$ & $44(23.3)$ \\
\hline $\begin{array}{l}\text { Clinical pharmacist can improve overall patient outcome/quality } \\
\text { of patient care. }\end{array}$ & $168(88.9)$ & $19(10.1)$ & $2(1.1)$ \\
\hline Overall perception Mean \pm Std. Deviation & $4.1 \pm 0.7$ & & \\
\hline
\end{tabular}

The effect of period of working experience of respondents on perception items:

The period of working experience in healthcare system of respondents did not have significant influence on all perception times except item number 12 which was about improving overall outcome/quality of patients' care with clinical pharmacy services. The respondents with more than ten years working experiences in healthcare system showed significantly $(P<0.05)$ better perception when compared with the respondents with 2-5 years of experiences only, using Scheffe test (Fig.1).
The effect of the working experience of respondents' and their perceptions on the appropriateness of the hospital setting in providing clinical pharmacy services:

The perception of respondents and their experiences on the appropriateness of the hospital settings (infrastructure and environments) in providing clinical pharmacy services (item no. 11) was tested using t-test. The respondents with experiences of less than one year to more than 3 years showed significantly $(\mathrm{P}<0.001)$ better perception when compared with respondents without experience (Fig.2). 


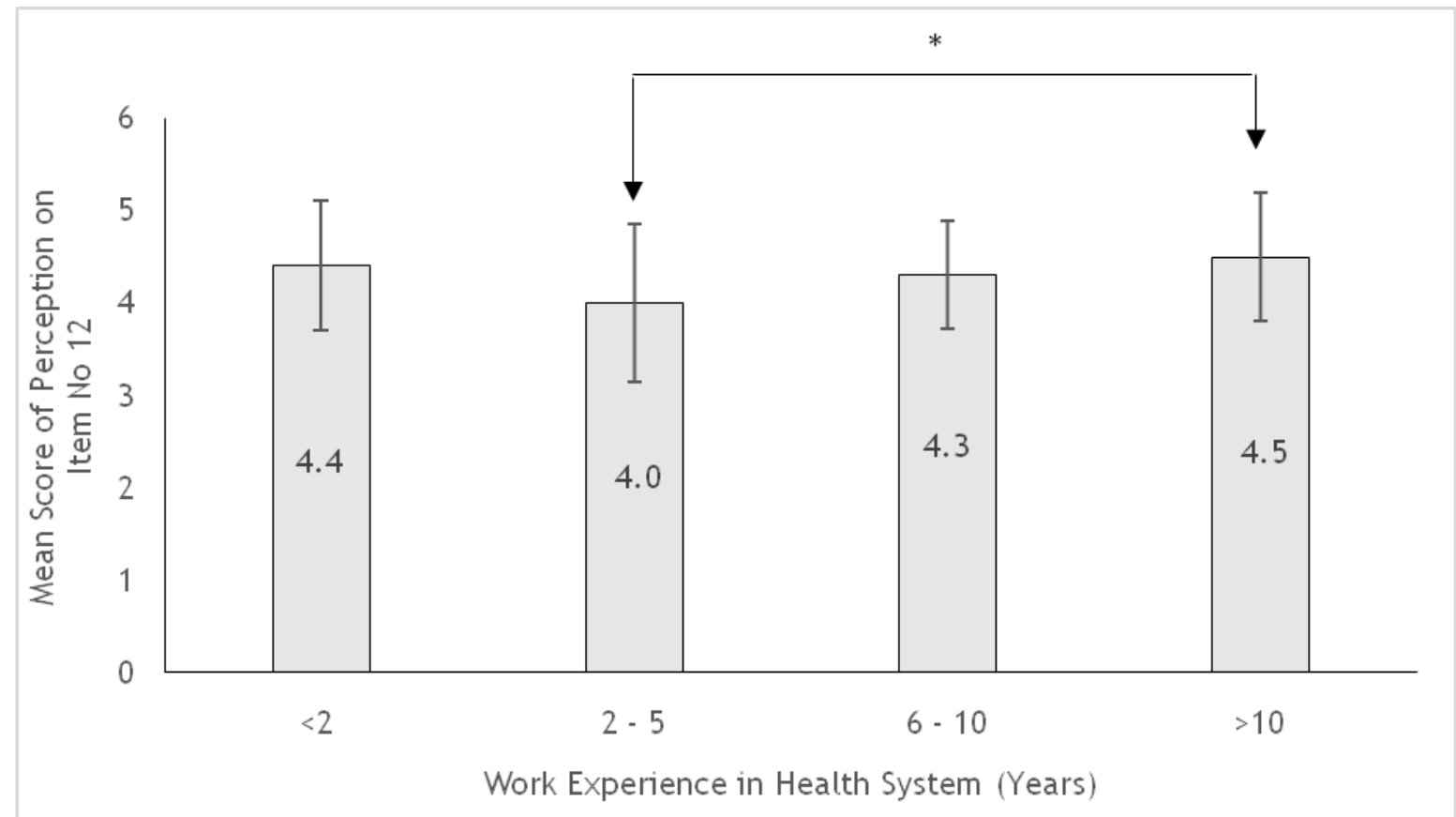

Values represent mean score of perception \pm Std. Deviation. The Scheffe test was used. The level of significance was set at $P<0.05$.

Fig1: The effect of physician's length of experience on their perception on the roles of clinical pharmacists on about item 12

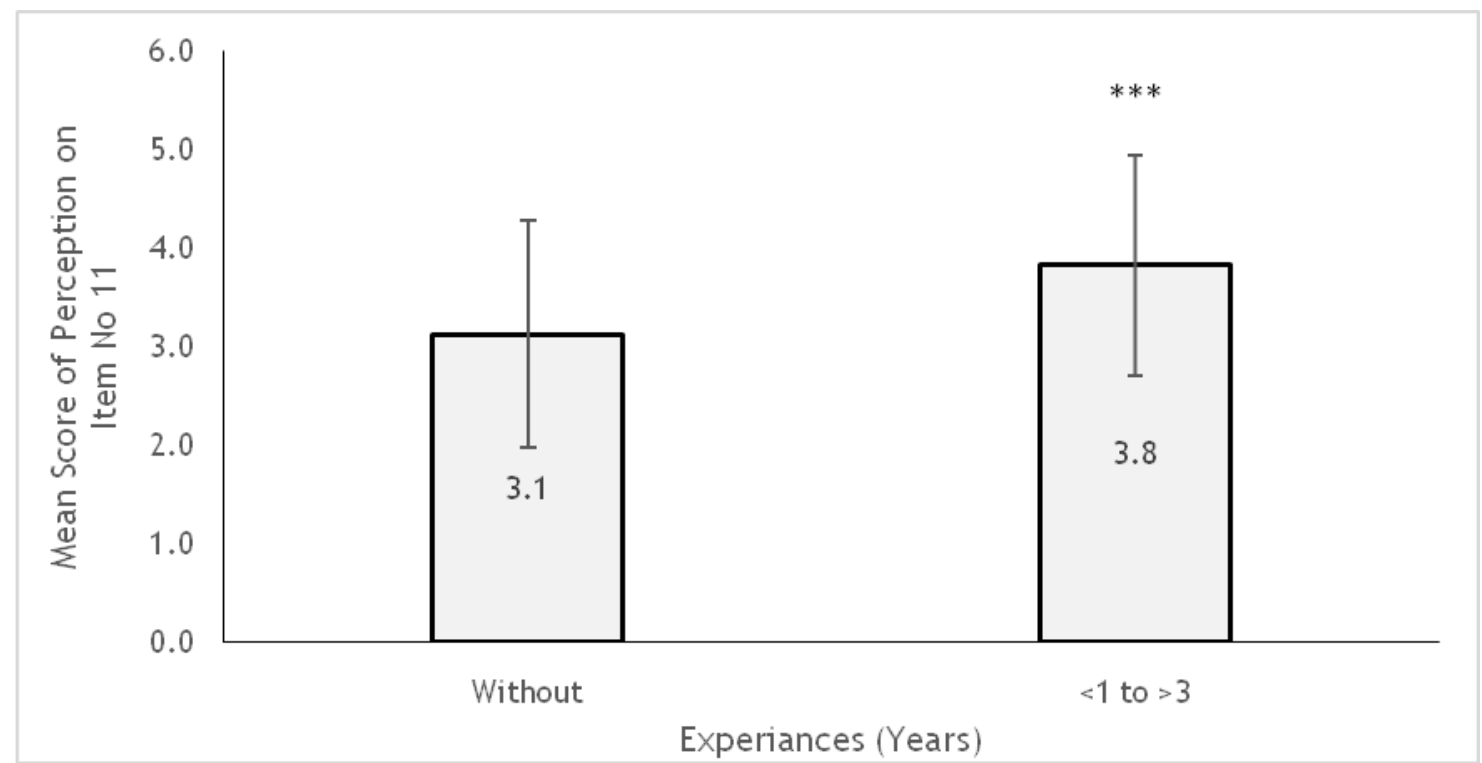

Values represent mean score of perception \pm Std. Deviation. The t-test was used. The level of significance was set at $P<0.05$.

Fig2: The effect physicians' experiences in health system with clinical pharmacy services on their perception on item No 11

\section{DISCUSSION}

The response rate in our study was $75.5 \%$ which is similar to a study conducted in Pakistan? Generally, the physicians at three governmental hospitals in Al Qassim showed moderate to high positive perceptions about clinical pharmacy services with $4.1 \pm 0.7$ as overall mean perception and standard deviation. This observation is in agreement with studies conducted in China by $\mathrm{Li}$ and his colleges $^{8}$ and Okoro and Auwal ${ }^{18}$ in Nigeria, that overall, the physicians showed positive perception about clinical pharmacy services. In contrast some studies did not agree with our study observations that physicians showed negative perceptions by 
not in favouring independent interventions in pharmacotherapy by clinical pharmacists. However, they all agreed to some of clinical activities like access to patient's medical records ${ }^{20,21}$. Some of the reasons for the negative perceptions may include the non-participation of physicians in activities of clinical pharmacist 9-12 or or the limited interactions of clinical pharmacists with physicians ${ }^{21}$; physicians' fear of losing independence and professional autonomy and clinical pharmacists perceived as inspectors of their work ${ }^{22}$. Additionally, the limited role and involvement of pharmacists and the communication gap between pharmacists and physicians in local healthcare settings may be important $^{24}$. The physicians often have positive attitude, if the clinical pharmacy services are provided in the form of consultations on medications or in support of knowledge-sharing with them to improve patients' care ${ }^{6-8,23}$.

On whether clinical pharmacists can monitor patients' response to drug therapy from the perspectives of drug toxicities and side effects, a large group of respondents (96\%) agreed. Similarly, regarding the ability of clinical pharmacists to monitor patients' responses to drug therapy from the effectiveness perspective, a large group of respondents (94\%) agreed. In a study conducted in Jordan by AbuRuzet $\mathrm{al}^{17}$, only (17.6\%) have negative perception about pharmacists providing patients follow-up and monitoring services. Moreover, Matowe and colleges $^{13}$ found that $57 \%$ of physicians were fairly comfortable with pharmacists in the implementation of patient-oriented roles such as designing and monitoring pharmacotherapeutic regimes, monitoring outcomes of pharmacotherapeutic regimens and detecting and preventing prescription errors. Our results are consistent with these results, and the positive perception regarding the ability of pharmacist to monitor drug therapy may be due to the positive experience of physicians in a healthcare setting with available of clinical pharmacy services. The majority of physicians (97.7\%) agreed that clinical pharmacists can provide drug information to health care professionals such as compatibility, stability, storage, availability. In a study conducted in United Arab Emirates (UAE), by Ibrahim et $\mathrm{al}^{14}$, two-thirds of physicians think that pharmacists can serve as a trusted source of information on general drug information, and about $25 \%$ of physicians think that pharmacists can be a trusted source about clinical information, and cost-effectiveness of medicines. Our results are consistent with these results which is logical results because clinical pharmacists are knowledgeable and professionally competent in drug information which is why they can provide this service to healthcare professionals.

Regarding the tenth Item which is apparently the only negative statement, that clinical pharmacists should care about drug products and leave patient care to Doctors, Health Officers and nurses, the perceptions of the physicians in the study were negative. This is one of the services of clinical pharmacy that was found to be completely unfavourable by physicians ${ }^{24,25}$. Among the reasons for this unfavourable perception are, the existence of a communication gap between clinical pharmacists and physicians and the absence of clinical pharmacists' roles in offering service ${ }^{26}$. An issue related to physicians is the lack of understanding of the clinical pharmacists' roles $^{19}$, where SCPs is viewed as an incursion into their own domain and could potentially damage the doctor-patient relationship ${ }^{25}$. The physicians' apprehension of losing independence is one of the major barriers for the negative attitude towards clinical pharmacists being perceived as inspectors of their work ${ }^{8,9}$.

Generally, respondents with different working experience in healthcare system showed positive perception with overall perception average of $4.2 \pm 0.2$ on the roles of clinical pharmacists on overall outcome/quality of patients' care. Younger physicians with less experience have introduce to clinical pharmacy services ${ }^{20}$. However, the working experiences of the respondents on clinical pharmacy services in healthcare sitting do not influence their perception of the roles of clinical pharmacists on overall outcome/quality of patient care. In other study working experiences of the respondents have influenced the acceptance of the SCPs by physicians and other members of the healthcare team ${ }^{20}$. Our study shows significant differences in response of respondents with experience to the acceptance of clinical pharmacists when compared with those without experience. The respondents with a range of less than 1 year to more 3 years of working experience showed significantly higher $(P<0.001)$ overall perception mean when compared with the respondents of none-experience to the perception item number 11 , on whether the current setup (infrastructure and environments) of your hospital is appropriate for the provisions of clinical pharmacy service. The physicians' experience in healthcare sitting with a developed clinical pharmacy services and greater awareness regarding the role of SCPs in patient care appear to improve physicians' perception of clinical pharmacists in health team $^{11,21}$.

\section{CONCLUSION}

Physicians' perception toward clinical pharmacy services (SCPS) and the role of clinical pharmacists was not found to be completely favourable. The reason for this mixed response to accommodating clinical pharmacy services in clinical settings was found to be related to the state of infrastructure and environments of hospitals. This often lead to a limitation in the 
role and involvement of pharmacists in the overall patients care. Furthermore it does not reduce the communication gap between pharmacists and physicians in local healthcare settings. The infrastructure and environments of hospitals need to be updated in order to accommodate clinical pharmacy services. Training of new practitioners on the art of setting up a health system with adequate provisions for clinical pharmacy services will help to improve their perceptions of the SCPs. Furthermore, it is highly recommending that intervention workshops be undertaken periodically to discuss the roles and implementing of clinical pharmacy services in modern healthcare systems. This will provide an avenue for discussing and recognizing the successes and limitations the desired environmental and infrastructural changes necessary for optimum SCPs by clinical pharmacists.

\section{LIMITATION OF THE STUDY}

The reported data in our study are subjected to some limitations. The study was conducted in only three hospitals at one city of Al Qassim region of Saudi Arabia, and the study only involved doctors in governmental hospitals and not those in private sector. The study has relatively small sample size. The data cannot be generalized. Furthermore, there was the possibility of a social response bias that a respondent may give a socially desirable response rather than what the respondents tactually believe.

\section{CONFLICTS OF INTEREST}

The authors declare that there are no conflicts of interest associated with the submitted manuscript.

\section{ACKNOWLEDGEMENTS}

The authors would like to express their appreciation for the physicians who participated in this research, the school of pharmacy and hospitals managements for their cooperation, assistant and supports. The authors also wish to thank Prof. Bala Yauri Muhammad and Dr. Abubakr A. Alfadl for proofreading.

\section{REFERENCES}

1. Canadian, Medical, Association. Approaches to enhancing the quality of drug therapy: a joint statement by the CMA and the Canadian Pharmaceutical Association [Canadian Medical Association Policy Summary]. Can Med Assoc J. 1996; 155:784A-D.

2. Hepler CD. Clinical pharmacy, pharmaceutical care, and the quality of drug therapy. Pharmacotherapy. 2004; 24(11):1491-1498.
3. Al-jedai A, Qaisi S, Al-meman A. Pharmacy practice and the health care system in Saudi Arabia. Can J Hosp Pharm 2016; 69(3):231.

4. Alomi YA. Looking to the future: Clinical pharmacy services in Saudi Arabia [abstract]. OMICS (ed). 8th International Conference and Exhibition on Pharmaceutics \& Novel Drug Delivery Systems. Madrid, Spain, 2016:7:1.

5. Alsultan MS, Khurshid F, Salamah HJ, et al. Hospital pharmacy practice in Saudi Arabia: Prescribing and transcribing in the Riyadh region. SPJ 2012; 20(3):20310.

6. Alkhateeb FM, Unni E, Latif D, et al. Physician attitudes toward collaborative agreements with pharmacists and their expectations of community pharmacists' responsibilities in West Virginia. J Am Pharm Assoc 2009; 49:797-800.

7. Azhar S, Hassali MA, Ibrahim M. Doctors' perception and expectations of the role of the pharmacist in Punjab, Pakistan. Trop J Pharm Res 2010; 9(3):205-22.

8. Li X, Huo H, Kong W, et al. Physicians' perceptions and attitudes toward clinical pharmacy services in urban general hospitals in China. Int J Clin Pharm 2014; 36(2):443-50.

9. Abduelkarem A, Sharif S. Current levels of interaction between the physician and pharmacist: A comparative study in Libya and UAE. Jordan J Pharm Sci 2008; 1:146-55.

10. Kheir $\mathrm{N}$, Zaidan $M$, Younes $\mathrm{H}$, et al. Pharmacy Education and Practice in 13 Middle Eastern Countries. Am J Pharm Educ 2008; 72:133-145.

11. Mekonnen AB, Yesuf EA, Odegard PS, et al. Physicians' expectation of clinical pharmacists' roles in Jimma University Specialized Hospital, South west Ethiopia. Int J Pharm Teach Practice 2013; 4(2):571-4.

12. Shah A. Pharmacy Intervention in the Medication Use Process: The Role of Pharmacists in ImprovingPatientSafety.2010.https://ww w.fip.org/files/fip/.../PatientSafetyAvid Shah.pdf. (Accessed 20 Dec 2015).

13. Mekonnen AB, Yesuf EA, Odegard PS, et al. implementing ward based clinical 
pharmacy services in an Ethiopian University Hospital. Pharm Practice 2013; 11(1):51-7.

14. Matowe L, Abahussain EA, Al-Saffar N, et al. Physicians' perceptions and expectations of pharmacists' professional duties in government hospitals in Kuwait. Med PrincPract 2006; 15(6): 185189.

15. Ibrahim M.O, Ibrahim R. Perception of Physicians to the Role of Clinical Pharmacists in United Arab Emirates. Pharmacology \& Pharmacy 2014; 5:895902.

16. AlmazrouS, Alnaim L,Al-Kofide $\mathrm{H}$. Perceptions, Expectations and Barriers of Physicians towards Working with Clinical Pharmacists in Saudi Arabia. AJSR 2015; 6(5): 404-415.

17. Bilal IS, Tilahun Z, Beedemariam G, et al. Attitude and satisfaction of health care providers towards clinical pharmacy services in Ethiopia. J Pharm Policy Pract 2016; 9(1):7-21

18. Okoro RN, Auwal MA. Hospital Pharmacists' Participation in Multidisciplinary Ward Rounds: Physicians' Perceptions and Attitudes. $\mathrm{Br}$ J Pharm Res 2015; 5(5):319-327.

19. AbuRuz SM, Al-Ghazawi MA, Bulatova N, et al. Expectations and experiences of physicians regarding pharmaceutical care and the expanding role of pharmacists in Jordan. Jordan JJPS 2012; 5(1): 2768.

20. Čufar A, Locatelli I, Mrhar A. Attitudes of physicians, nurses and pharmacists concerning the development of clinical pharmacy activities in a university hospital. Actapharmaceutica. 2014; 64(4):447-461.

21. Khdour MR, Alayasa KS, AlShahed QN, et al. Physicians' perceptions, attitudes and expectations regarding the role of hospital-based pharmacists in the West Bank, Palestine. IJPP 2013; 21(3):178-84.

22. Alkhateeb FM, Clauson KA, McCafferty R, et al. Physician attitudes toward pharmacist provision of medication therapy management services. PWS 2009; 31(4):487-493.

23. Awalom MT, Kidane ME, Abraha BW. Physicians' views on the professional roles of pharmacists in patient care in Eritrea. IJCP 2013; 35(5):841-6.

24. Iqbal MJ, Ishaq GM. Knowledge, attitude and perception of health care providers (HCPS) at internal medicine ward of a tertiary care hospital towards pharmaceutical care. Int $J$ Pharm Sci Res 2017; 8(2):831.

25. Awad A, Matowe L, Capps P. Medical doctors' perceptions and expectations of the role of hospital pharmacists in Sudan. PWS 2007; 29(5): 557-64.

26. Hirsch JD, Gagnon JP, Camp R. Value of pharmacy services: perceptions of consumers, physicians, and third party prescription plan administrators. Am pharm 1990; 30(3):20-5. 